\title{
Summary of Future Space Observations of Solar Irradiances at Different Wavelengths
}

\author{
By VICENTE DOMINGO
}

Space Science Department, European Space Agency, ESTEC, Noordwijk, The Netherlands

The variations of solar irradiance can only be measured with a reasonable precision from space for almost all wavelengths. Yet the history of solar irradiance determinations is, with few exceptions, the history of efforts to patch the infrequent or too discontinuous space-based measurements by devising mechanisms for proxy determination of solar irradiance fluxes from ground-based obtained parameters. Although it appears that in the near future the situation will not be too different, there is some increase in the coverage of the spectral range that will be monitored. From gamma-rays to infrared light there are instruments that are now operating (e.g. GOES, Yohkoh, UARS) or are planned to operate in approved space missions (e.g. SOHO, ATLAS), or form part of proposed, not yet approved, missions. New techniques are being developed specifically for the measurement of solar irradiance variations with increased precision (e.g. cryogenic radiometer) in the next generation of space-borne measurements.

\section{Introduction}

The observation of solar irradiance variations in the past is the object of several papers in these proceedings. Therefore we refer to those papers for a review of the status of the subject.

This paper summarizes what may be expected to be the coverage of solar irradiance measurements in the near future. To do so we list the spacecraft that are now in operation and carry solar irradiance measuring instruments, the spacecraft that will be launched in the near future because they are being built now and those that probably will be launched because, either they have been approved and not yet financed or are likely to be approved.

Although we are primarily interested in irradiance measuring instruments, we also list the imaging instruments because they can be used as an alternative to approximate the measurements of solar irradiance. Even though the irradiance obtained in this way will have a larger error than if obtained with a radiometer, but in the absence of direct irradiance observations it will be the best one that we can get.

\section{Spacecraft now in operation}

The following spacecraft carry instruments that measure the solar irradiance. These spacecraft have limited nominal lifetimes but it is expected that they will be maintained in operation as long as their instruments are operational (Reinhard \& Battrick 1990; RISE 1990).

- The Upper Atmosphere Research Satellite (UARS) is a spacecraft designed to provide the global data base necessary for understanding the coupled chemistry and dynamics of the stratosphere and mesosphere, the role of solar radiation in driving the chemistry and dynamics, and the susceptibility of the upper atmosphere to long-term changes in the concentration and distribution of key atmosphere constituents, particularly ozone. It carries instruments to measure the solar input: Active Cavity Radiometer Irradiance Monitor II (ACRIM II), Solar-Stellar Irradiance Monitor (SOLSTICE) and Solar Ultraviolet Spectral Irradiance Monitor (SUSIM). Details of these experiments are 


\begin{tabular}{|c|c|c|c|c|}
\hline $\begin{array}{l}\text { Spacecraft } \\
\text { \& launch }\end{array}$ & Lifetime & Experiment & Wavelength & $\begin{array}{l}\text { Spectral } \\
\text { resolution }\end{array}$ \\
\hline $\begin{array}{c}\text { UARS } \\
1991\end{array}$ & $\begin{array}{c}\text { design: } 3 \text { yrs } \\
\text { expectation: } \\
\text { a few years } \\
\text { more }\end{array}$ & $\begin{array}{l}\text { ACRIM II } \\
\text { SUSIM } \\
\text { SOLSTICE }\end{array}$ & $\begin{array}{c}\text { total irradiance } \\
120-400 \mathrm{~nm} \\
115-430 \mathrm{~nm}\end{array}$ & $\begin{array}{c}0.15 \text { or } 5 \mathrm{~nm} \text { step } \\
0.12 \mathrm{~nm} \text { step }\end{array}$ \\
\hline NOAA-9, -11 & $\begin{array}{l}\text { Continuous } \\
\text { series of } S / C\end{array}$ & $\mathrm{SBUV} / 2$ & $160-405 \mathrm{~nm}$ & 1nm step \\
\hline GOES & $\begin{array}{l}\text { Continuous } \\
\text { series of } S / C\end{array}$ & $1-8 \AA$ & & \\
\hline $\begin{array}{c}\text { ATLAS } \\
\text { once per year, } \\
\text { one solar cycle } \\
\text { (to about 2002) }\end{array}$ & $7-9$ days & $\begin{array}{c}\text { ACRIM } \\
\text { SOLCON } \\
\text { SOLSPEC } \\
\text { SUSIM }\end{array}$ & $\begin{array}{c}\text { total irradiance } \\
\text { total irradiance } \\
170-320 \mathrm{~nm} \\
120-400 \mathrm{~nm}\end{array}$ & $\begin{array}{l}\text { step: } 1 \mathrm{~nm} \text { visible } \\
20 \mathrm{~nm} \text { infrared } \\
0.15 \text { or } 5 \mathrm{~nm} \text { step }\end{array}$ \\
\hline $\begin{array}{c}\text { Yohkoh } \\
1991\end{array}$ & $\begin{array}{c}\text { design life } \\
\text { will expire in } \\
\text { August 1994, } \\
\text { expected several } \\
\text { years more }\end{array}$ & WBS & $\begin{array}{c}\text { S XV line }(5.0385 \AA) \\
\text { CA XIX }(3.1769) \\
\text { FE XXV }(1.8509) \\
\text { Fe XXVI }(1.7780) \\
2-30 \mathrm{keV}, \\
20-400 \mathrm{keV}, \\
0.2-100 \mathrm{MeV}\end{array}$ & \\
\hline
\end{tabular}

TABLE 1. Now operating spacecraft: Solar irradiance (see explanation of experiment acronyms in the main text).

given in this volume by Willson (1994), Rottman et al. (1994), and Brueckner et al. (1994). It orbits the Earth at $600 \mathrm{~km}$ altitude, at an inclination of 57 degrees. Launched in September 1991, its design lifetime ends in 1994, but it is expected to be operational for several more years.

- The Atmospheric LAboratory Spacecraft (ATLAS) is a platform that is brought into space within the cargo bay of the Space Shuttle, about once a year. The duration of the observations is of the order of 10 to 20 hours in a span of about 7 to 9 days. The last flight took place in April 1993. The next one is planned for 1994, and thereafter once a year until about 2001. It carries two total solar irradiance (solar constant) measuring instruments, the Active Cavity Radiometer Irradiance Monitor (ACRIM) and the Solar CONstant experiment (SOLCON), both of the electrical substitution radiometer type (Willson 1994; Crommelynck et al. 1994), SOLar SPECtrum (SOLSPEC) (Thuillier et al. 1994) and the SUSIM, already mentioned in the description of UARS, instruments measuring the spectral solar irradiance.

- The National Oceanographic and Atmospheric Administration satellites, NOAA-9 and NOAA-11 form part of a continuing program to monitor the Earth's atmosphere. They carry an instrument (SBUV/2) that monitors the solar ultraviolet spectrum (Cebula et al. 1994).

- The Geostationary Operational Environment Satellite (GOES) series continues monitoring the high energy region of the spectrum, sensitive to energetic solar activity (Aschwanden 1994) 


\begin{tabular}{|c|c|c|c|c|}
\hline $\begin{array}{l}\text { Spacecraft } \\
\& \text { launch }\end{array}$ & Lifetime & Experiment & Wavelength & $\begin{array}{l}\text { Spatial } \\
\text { resolutior }\end{array}$ \\
\hline \multirow[t]{2}{*}{$\begin{array}{c}\text { Yohkoh } \\
1991\end{array}$} & $\begin{array}{c}\text { design life } \\
\text { will expire in }\end{array}$ & SXT & $0.3-6 \mathrm{~nm}$ & $2.5 "$ \\
\hline & $\begin{array}{l}\text { August 1994, } \\
\text { expected several } \\
\text { years more }\end{array}$ & HXT & $\begin{array}{c}15-100 \mathrm{keV} \\
(4 \text { bands) }\end{array}$ & $5 "$ \\
\hline
\end{tabular}

TABLE 2. Now operating spacecraft: Solar imaging experiments (see explanation of experiment acronyms in main text).

\begin{tabular}{|c|c|c|c|c|}
\hline $\begin{array}{l}\text { Spacecraft } \\
\text { \& launch }\end{array}$ & Lifetime & Experiment & Wavelength & $\begin{array}{l}\text { Spectral } \\
\text { resolution }\end{array}$ \\
\hline \multirow[t]{2}{*}{$\begin{array}{l}\text { Coronas } \\
\text { early } 1994\end{array}$} & $\begin{array}{c}1 \text { year, } \\
\text { more expected }\end{array}$ & & $\begin{array}{c}0.3-2.5,0.3-12 \\
121.6(\text { HLy- } \alpha),<130 \mathrm{~nm}\end{array}$ & \\
\hline & & $\begin{array}{l}\text { VUSS } \\
\text { IRIS } \\
\text { DIFOS }\end{array}$ & $\begin{array}{c}20-58 \mathrm{~nm} \\
2-300 \mathrm{keV} \text {, diverse bands } \\
520,710 \\
400-1000 \mathrm{~nm}\end{array}$ & $\begin{array}{l}\mathrm{L} / \mathrm{DL}=400 \\
\text { bandpass } \\
100 \mathrm{~nm}\end{array}$ \\
\hline \multirow[t]{2}{*}{$\begin{array}{l}\text { SOHO } \\
\text { July } 1995\end{array}$} & $\begin{array}{c}2 \text { years } \\
(+4 \text { possible })\end{array}$ & & $\begin{array}{c}\text { total irradiance } \\
402,500,862 \mathrm{~nm}\end{array}$ & bandpass $5 \mathrm{~nm}$ \\
\hline & & SEM & $30.5 \mathrm{~nm}$ & \\
\hline $\begin{array}{l}\text { TIMED } \\
2000-2001\end{array}$ & 2 years & SEE & $\begin{array}{l}0.1-200,0.1-35 \\
0.1-90 \mathrm{~nm}\end{array}$ & $\begin{array}{c}\text { step 1nm, ? } \\
?\end{array}$ \\
\hline
\end{tabular}

TABLE 3. Future spacecraft: Solar irradiance (see explanation of experiment acronyms in the main text).

- The Yohkoh satellite is a mission to investigate high energy phenomena on the Sun through X-ray and gamma-ray observations. The Hard X-ray Telescope (HXT) and the Soft X-ray Telescope (SXT) produce images of the solar corona, and the Wide Band Spectrometer (WBS) and the Bragg Crystal Spectrometer (BCS) monitor several spectral lines and bands both in the soft X-rays and in the hard X-and gamma-rays regions of the spectrum (see details by Shibata 1994). Launched in 1991, it has completed its design lifetime but is expected to remain operational for several years. It orbits the Earth at about $600 \mathrm{~km}$ altitude in a low inclination orbit.

Tables 1 and 2 summarize the main characteristics of the solar monitoring experiments now in operation.

\section{Spacecraft now being built and planned spacecraft}

We include here spacecraft that are now under development, spacecraft that have been approved, but have not been funded yet, and one spacecraft that has been proposed for funding, but is not yet approved.

- Coronas- $I$ is a mission to investigate solar flares in a broad range of the electromagnetic spectrum complemented by an instrument to measure solar luminosity oscillations for helioseismological research. Coronas will be placed in a quasi sun-synchronous orbit at $500 \mathrm{~km}$ altitude. It will be launched in early 1994, with a nominal lifetime of 1 


\begin{tabular}{|c|c|c|c|c|}
\hline $\begin{array}{l}\text { Spacecraft } \\
\text { \& launch }\end{array}$ & Lifetime & Experiment & Wavelength & $\begin{array}{l}\text { Spatial } \\
\text { resolution }\end{array}$ \\
\hline $\begin{array}{c}\text { Coronas } \\
1994\end{array}$ & $\begin{array}{l}1 \text { year } \\
+\end{array}$ & RES-C & $\begin{array}{c}190-205 \\
8.41-8.43 \\
1.85-1.87 \AA\end{array}$ & $\begin{array}{c}6 " \times 90 " \\
6 " \times 6 " \\
2\end{array}$ \\
\hline $\begin{array}{c}\text { SOHO } \\
1995\end{array}$ & $\begin{array}{c}2 \text { years } \\
(+4)\end{array}$ & $\begin{array}{l}\text { VIRGO/LOI } \\
\text { MDI } \\
\text { SUMER } \\
\text { CDS } \\
\text { EIT }\end{array}$ & $\begin{array}{c}500 \mathrm{~nm} \\
6768 \AA \\
50-160 \mathrm{~nm} \\
15-80 \mathrm{~nm} \\
171 \AA \mathrm{FeIX}, 195 \mathrm{FeXII} \\
284 \mathrm{FeXV}, 304 \mathrm{HeII}\end{array}$ & $\begin{array}{c}8^{\prime}(12 \text { pixels }) \\
\text { 4" and 1" } \\
2 " \\
3 " \\
\text { 5" }\end{array}$ \\
\hline $\begin{array}{c}\text { GOES-7 } \\
1997\end{array}$ & $\begin{array}{l}\text { continuous } \\
\text { series }\end{array}$ & $\begin{array}{c}\text { X-ray } \\
\text { imager }\end{array}$ & $1-8 \AA$ & $1-2 "$ \\
\hline $\begin{array}{c}\text { SWATH } \\
1996(?)\end{array}$ & 1 year & $\begin{array}{l}\text { XUV } \\
\text { telescope }\end{array}$ & $193 \AA$ & $1 "$ \\
\hline $\begin{array}{l}\text { TRACE } \\
1997\end{array}$ & 1 year & & $\begin{array}{c}3500,1700,1570,1550 \\
1216,285,195,171 \AA\end{array}$ & $1 "$ \\
\hline
\end{tabular}

TABLE 4. Future spacecraft: Solar imaging experiments (see explanation of experiment acronyms in the main text).

year. Coronas carries instruments that monitor the electromagnetic spectrum in many wavelength bands from X-rays to ultraviolet. Particularly interesting, for the subject of this conference, are the Solar Ultraviolet Radiometer (SUVR) and the Vacuum Ultraviolet Solar Spectrometer (VUSS). The 3-channel solar white light photometer provides continuous measurement of 3 spectral bands in the visible. The Solar X-ray Spectrometer (RES-C) produces monochromatic images of the Sun in three spectral ranges in the EUV and soft $\mathrm{X}$-ray ranges.

- The Solar and Heliospheric Observatory ( $\mathrm{SOHO}$ ) has been designed to study the physics of the solar corona, the generation of the solar wind and the internal structure of the Sun. For that it carries instruments that will perform helioseismic measurements, spectroscopic plasma diagnostics and in situ solar wind particle analysis measurements. SOHO will be in a heliocentric orbit around the L1 Sun-Earth Lagrangian point. It will be launched in July 1995, with a nominal lifetime ending in December 1997, but with consumables that will allow it to stay at least another 4 years. The Variations of Solar Irradiance and Global Oscillations (VIRGO) experiment will perform total solar irradiance (solar constant) measurements and spectral irradiance measurements in the visible, in 3 wavelength bands, each about $5 \mathrm{~nm}$ wide. The Solar Extreme-ultraviolet Monitor (SEM) instrument monitors the EUV radiation around $30.5 \mathrm{~nm}$. Several instruments will produce images of the full solar disk in the EUV wavelength range (Solar Ultraviolet Measurements of Emitted Radiation - SUMER, Coronal Diagnostic Spectrometer CDS, and Extreme-ultraviolet Imaging Telescope - EIT) and one, the Michelson Doppler Imager (MDI) will produce images in the visible.

- The Space Weather and Terrestrial Hazards (SWATH) experiment is designed to place into low-Earth orbit a set of instruments for measurement and study of local space hazards. The mission has three major scientific objectives: 1.) to monitor, track and 
study large disturbances originating at the Sun and propagating to the near-Earth environment; 2.) to monitor and study the activity of the solar corona; 3.) to track and measure space debris in low-earth orbit. It carries a small XUV telescope operating at $193 \AA$ wavelength, which images the solar corona at two million degrees temperature. A second telescope contains a large multilayer-coated mirror for imaging of the solar corona at arcsecond spatial resolution; a moveable filter also provides imaging of the solar photosphere at high resolution. The satellite will be placed in a polar, sun-synchronous orbit for nearly continuous monitoring of the Sun and for pole-to-pole mapping of the space debris populations. If funding is confirmed it could be launched in 1996 .

- A new GOES satellite, to be launched around 1997 (?) will carry an X-ray imager operating in the 1-8 $\AA$ band.

- The Thermosphere-Ionosphere-Mesosphere Energetics and Dynamics (TIMED) mission is intended to carry out the first detailed, space-based study of physical and chemical processes in the terrestrial atmosphere between about 60 and $180 \mathrm{~km}$ altitude. It has not yet been funded, but it is planned to be launched around 2000 or 2001 with a nominal lifetime of 2 years. It will carry a Solar EUV Experiment (SEE) measuring spectral irradiance between 0.1 and $200 \mathrm{~nm}$ with a combination of spectrometers and filtered photodiods.

- TRACE - the Transition Region And Coronal Explorer is a single-instrument solar mission to be put into a sun-synchronous polar orbit and will obtain continuous solar observations for about 8 months per year. It will collect images of the Sun at 8 wavelength bands, between 17 and $250 \mathrm{~nm}$, with 1-arcsec spatial resolution and excellent temporal resolution and continuity. At the moment TRACE is a proposed mission that, if approved, could be launched around 1997-1998.

Tables 3 and 4 list the main characteristics of the experiments being developed and expected to be in space in the immediate future. Figures 1 and 2 summarize the spectral coverage versus the expected solar radiometric observations.

\section{Conclusion}

\subsection{Solar total irradiance (solar constant)}

Given the accuracy of the absolute radiometers (Fröhlich 1994), the discovery of the variation of the solar constant during a solar cycle was possible because the solar irradiance measuring instruments aboard NIMBUS-7, the Solar Maximum Mission (SMM), and the Earth Radiation Budget Satellite (ERBS) were operating long enough in a continuous manner.

The variation of the solar constant from cycle to cycle is expected to be well below one part per thousand. Since the present generation of radiometers can only measure the solar irradiance with an absolute precision of the same order, one can expect to observe these long-term variations only if one observes with one radiometer continuously, or if one is able to offset the relative instrumental error between two or more radiometers by performing simultaneous measurements of the solar constant with them and comparing the results.

The successful series of measurements started with NIMBUS-7, the Solar Maximum Mission and ERBS and continued by the ACRIM II instrument aboard UARS may, if UARS operates long enough, be connected with the measurements that will start to be made from SOHO in the second half of 1995 (Figure 1). If this is so the solar constant variation along one solar cycle detected by the ACRIM instrument may be continued to be observed during a second solar cycle. The chart (Figure 1) also shows that, unless 


\section{SOLAR IRRADIANCE MEASUREMENTS}

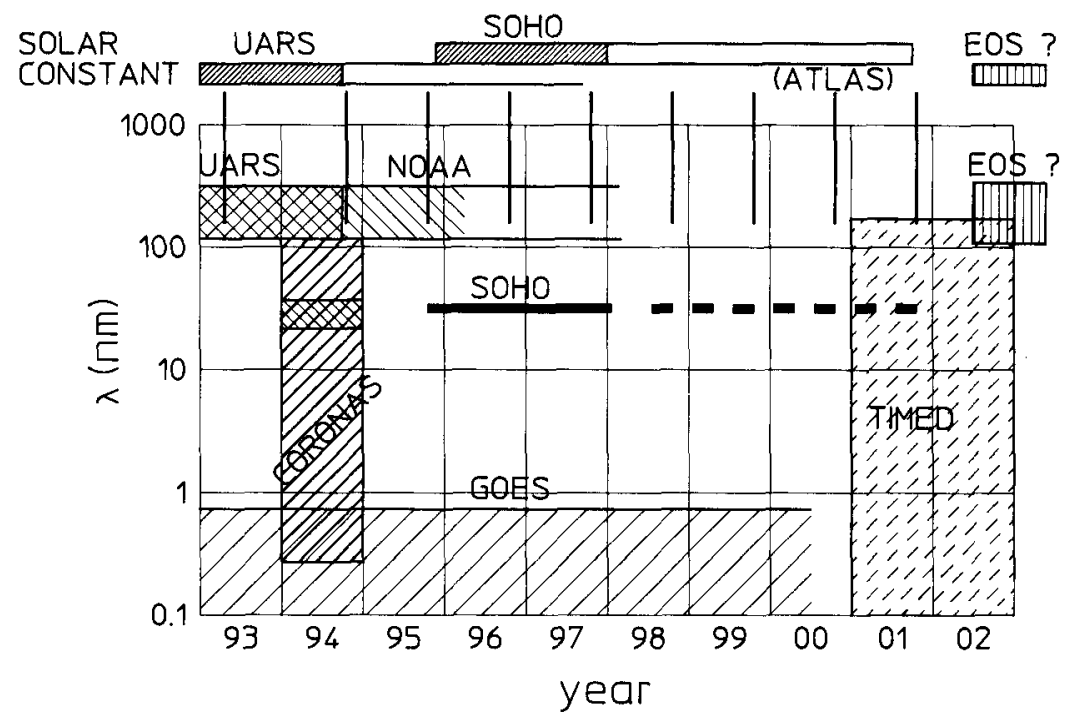

Figure 1. Time history of the expected solar irradiance measurements in the present decade at different wavelengths (the acronyms of the spacecraft are explained in the main text).

some action is undertaken by the space agencies, there is a large probability that the solar constant measurement series will be interrupted after SOHO. To be able to observe longer time trends in solar variations (those that may be of significance for the Earth's climate) the space agencies should make sure that continued measurements of well intercompared instruments are continued for the next solar cycles.

A complementary action that should be taken is to support the development and operation in space of a new generation of radiometers with higher absolute precision such as the cryogenic radiometers that are being proposed for future observations (Martin \& Fox 1992). Increasing the current absolute precision (about $\pm 0.15 \%$ ) of the measurements by about an order of magnitude may eliminate the need to obtain continuous measurements made with the same instrument or with instruments that have been compared in space with the previous ones.

\subsection{Spectral irradiance measurements}

The two main regions of the electromagnetic spectrum of interest for aeronomy are the Ultraviolet (UV), from Lyman- $\alpha$ to $400 \mathrm{~nm}$, and the Extreme Ultraviolet (EUV), $5 \mathrm{~nm}$ to Lyman- $\alpha$.

There is a continuous monitoring of the solar UV from the NOAA satellites that will last at least until 2000, and in addition now UARS is producing measurements from its two UV radiometers. Some time after 2000, the Earth Observation System (EOS) will carry a UV instrument as well, but the launch dates are not yet fixed.

More unclear are the prospects of EUV continuous monitoring. From now to the indefinite future $(>2000)$, the only programs that include EUV monitoring are Coronas, to be launched in 1994, SOHO, starting late 1995, and TIMED, possibly around 2000-2001. Such measurements are not easy, but they are needed for upper atmosphere research. 


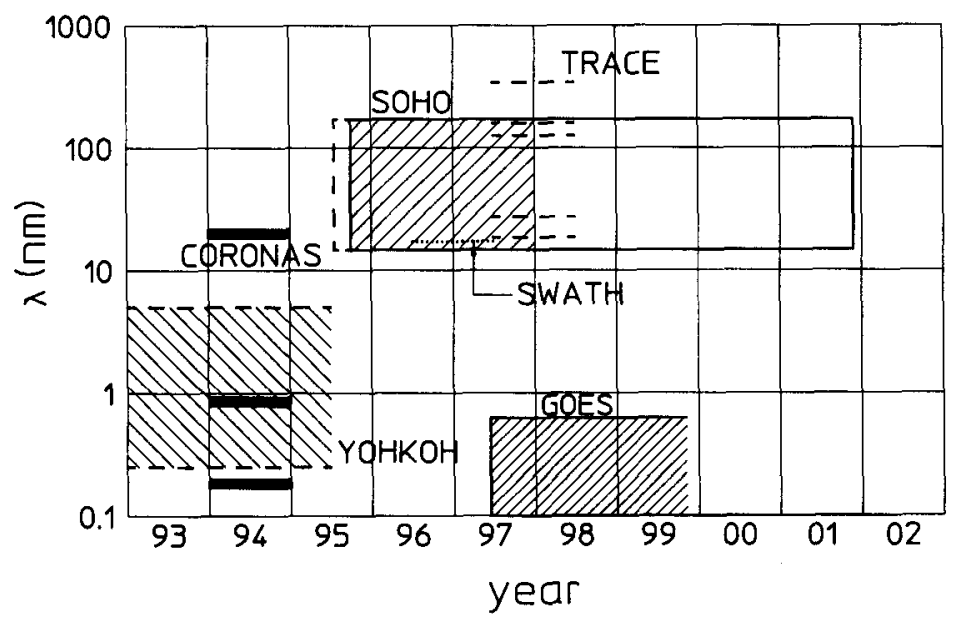

FIGURE 2. Time history of the expected solar imaging observations from space, in the present decade, that may be useful for radiometric measurements (the acronyms of the spacecraft are explained in the main text).

\subsection{Solar imaging experiments}

The solar imaging instruments have not been conceived to obtain radiometric results, yet when there are no better measurements they can be used to determine the solar irradiance by careful integration of the images. This will be the case of the EUV instruments aboard SOHO, that will be able to produce radiometric measurements of the EUV irradiance. These measurements will have, of course, limited accuracy, but they will be an improvement over the proxy indices (Tobiska \& Barth 1990) used now to compute the solar EUV fluxes. Figure 2 represents the expected supplementary cover that the solar imaging instruments will provide over the following years.

\section{REFERENCES}

Aschwanden, M. 1994 Irradiance observations from the GOES satellite. Solar Phys., in press. Brueckner, G., Floyd, L.E., Lund, P.A., Prinz, D.K. \& VanHoosier, M.E. 1994 Irradiance observations from the UARS/SUSIM and ATLAS/SUSIM Experiments. In The Sun as a Variable Star: Solar and Stellar Irradianec Variations (ed. J.M. Pap, C. Fröhlich, H.S. Hudson \& S.K. Solanki). Cambridge Univ. Press, in press.

Cebula, R.P., Hilsenrath, E. \& Deland, M.T. 1994 Middle ultraviolet solar spectral irradiance measurements, 1985-1992, from the SBUV/2 and SSBUV instruments. In The Sun as a Variable Star: Solar and Stellar Irradiance Variations (ed. J.M. Pap, C. Fröhlich, H.S. Hudson \& S.K. Solanki). Cambridge Univ. Press, in press.

Crommelynck, D., Domingo, V., Fichot, A. \& LeE, R. 1994 Solar irradiance observations from the EURECA and ATLAS experiments. In The Sun as a Variable Star: Solar and Stellar Irradiance Variations (ed. J.M. Pap, C. Fröhlich, H.S. Hudson \& S.K. Solanki). Cambridge Univ. Press, in press.

Fröhlich, C. 1994 Irradiance observations of the Sun. In The Sun as a Variable Star: Solar and Stellar Irradiance Variations (ed. J.M. Pap, C. Fröhlich, H.S. Hudson \& S.K. Solanki). Cambridge Univ. Press, in press.

REINHARD, R. \& BATTRICK, B. 1990 Inter-Agency Consultative Group for Space Science (IACG). Key Data on Participating Projects ESA-SP- 1107. Paris, November 1990.

RISE 1990 Radiative Inputs of the Sun to Earth. A Research Plan for the 1990's on Solar 
Irradiance Variation. National Science Foundation Report. February 1990.

Martin, J. E. \& Fox, N. P. 1992 Absolute radiometric measurements in space. In Proceedings of an ESA Syposium on Photon Detectors for Space Instrumentation ESA SP-356, December 1992.

RotTMAN, G.J., WoODS, T.N, WhITE, O.R. \& London, J. 1994 Irradiance observations from the UARS/SOLSTICE experiment. In The Sun as a Variable Star: Solar and Stellar Irradiance Variations (ed. J.M. Pap, C. Fröhlich, H.S. Hudson \& S.K. Solanki). Cambridge Univ. Press, in press.

Shibata, K. 1994 The variable structure of the X-ray corona as viewed by Yohkoh. In The Sun as a Variable Star: Solar and Stellar Irradiance Variations (ed. J.M. Pap, C. Fröhlich, H.S. Hudson \& S.K. Solanki). Cambridge Univ. Press, in press.

Tobiska, W.K. \& Barth, C.A. 1990 A solar EUV Flux model. J. Geophys. Res. 95, 8243-8251.

WILlson, R.C. 1994 Irradiance observations of SMM, Spacelab 1, UARS, and ATLAS experiments. In The Sun as a Variable Star: Solar and Stellar Irradiance Variations (ed. J.M. Pap, C. Fröhlich, H.S. Hudson \& S.K. Solanki). Cambridge Univ. Press, in press. 